\title{
Air-liquid interface cultures enhance the oxygen supply and trigger the structural and functional differentiation of intestinal porcine epithelial cells (IPEC)
}

\author{
Constanze Nossol $\cdot$ A.-K. Diesing $\cdot$ N. Walk \\ H. Faber-Zuschratter $\cdot$ R. Hartig $\cdot$ A. Post $\cdot$ \\ J. Kluess $\cdot$ H.-J. Rothkötter $\cdot$ S. Kahlert
}

Accepted: 23 May 2011/Published online: 17 June 2011

(C) The Author(s) 2011. This article is published with open access at Springerlink.com

\begin{abstract}
The specific function of the epithelium as critical barrier between the intestinal lumen and the organism's internal microenvironment is reflected by permanent maintenance of intercellular junctions and cellular polarity. The intestinal epithelial cells are responsible for absorption of nutritional components, facing mechanical stress and a changing oxygen supplementation via blood stream. Oxygen itself can regulate the barrier and the absorptive function of the epithelium. Therefore, we compared the dish cell culture, the transwell-like membrane culture and the oxygen enriched air-liquid interface (ALI) culture. We demonstrated strong influence of the different culture conditions on morphology and function of intestinal porcine epithelial cell lines in vitro. ALI culture resulted in a significant increase in cell number, epithelial cell layer thickness and expression as well as apical localisation of the microvilli-associated protein villin. Remarkable similarities regarding the morphological parameters were observed between ALI cultures and intestinal epithelial cells in vivo. Furthermore, the functional analysis of protein uptake and degradation by the epithelial cells demonstrated the necessity of sufficient oxygen supply as achieved in ALI cultures. Our study is the
\end{abstract}

C. Nossol $(\bowtie) \cdot$ A.-K. Diesing · N. Walk ·

H. Faber-Zuschratter - A. Post - J. Kluess - H.-J. Rothkötter ·

S. Kahlert

Institute of Anatomy, Medical Faculty, Otto-von-Guericke

University Magdeburg, Leipziger Strasse 44,

39120 Magdeburg, Germany

e-mail: constanze.nossol@med.ovgu.de

R. Hartig

Institute of Molecular and Clinical Immunology, Medical Faculty, Otto-von-Guericke University Magdeburg, Leipziger

Strasse 44, 39120 Magdeburg, Germany first report providing marked evidence that optimised oxygen supply using ALI cultures directly affects the morphological differentiation and functional properties of intestinal epithelial cells in vitro.

Keywords Intestinal porcine epithelia $\cdot$ Air-liquid interface culture · Villin - Epithelial morphology . Differentiation · Protein uptake

\section{Introduction}

The intestinal epithelial cells form a highly dynamic border between the external (mucosal/luminal) and internal (serosal/vascular) compartment. The epithelial function requires the maintenance of intercellular junctions (zona occludentes) and the organisation of cellular polarity (brush border and lateral intercellular spaces). Additionally, intestinal epithelial cells face highly variable conditions regarding pressure, mechanical stress and oxygen supply. The dynamic intestinal barrier is responsible for digestion, selective uptake and transport of nutrients from the gut lumen to the bloodstream. Interestingly both, the barrier and the ion transport capacity of intestinal epithelial layers are regulated by oxygen (Friedman et al. 1998; Taylor et al. 1998). In vitro models used for the analysis of intestinal epithelial function must consider the nutrition and oxygen supply of the epithelial cells. Often cell cultures are grown on an impermeable plastic surface coated with relevant biological components (Glaum et al. 2010). This set up is far away from intact tissue, because enterocytes receive nutrients from the apical and basolateral side. Moreover, oxygen is transported via the blood and reaches the basolateral aspect of the epithelial cells (Storch et al. 2008). The epithelial cells cultured on conventional 
plastic dishes need to adapt to exclusive apical nutrient supply. The introduction of membrane culture systems, e.g. the Transwell ${ }^{\mathrm{TM}}$ system (Corning, NY, USA) offers conditions reflecting the epithelial barrier more closely. The membranes with suitable pore sizes mimic the basal membrane, thus enabling in vitro cultivation of intestinal epithelial cells close to the physiological conditions (FeyLamprecht et al. 2000). Moreover, the permeable support and the presence of the basolateral fluid compartment allow also both the apical uptake and basolateral secretion. This is essential as the major epithelial function is indeed a selective and high capacity transport of ions, peptides and other nutrients to the subepithelial compartment (Daniel 2004). However, despite the advantages of transwell-like membrane cultures this methodology does not fully meet the requirement of those metabolic highly active and hypoxia-sensitive intestinal epithelial cells (Lewis and McKay 2009). In the dish cell cultures and also in conventional membrane cultures, the cells are covered completely with culture medium. This limits the oxygen supply dramatically. Therefore, in literature, the more sensitive primary epithelial cells were mostly cultured with oxygenised media (Bader et al. 2000). Interestingly, conventional membrane cultures, in which the apical epithelial side is just covered by a thin liquid film, so called airliquid interface (ALI) cultures, are state of the art for in vitro cultivation of airway and gastric epithelial cells (Gruenert et al. 1995; Ootani et al. 2000). The application of the ALI technique on gastric mucosa cell cultures improved the morphological and functional properties of the gastric culture system GSM06 (Ootani et al. 2000; Yokoyama et al. 2007). By reducing the apical medium volume to a thin film, the diffusion barrier is minimised, thus resulting in an enhanced oxygen supply to a level, which likely meets the requirements of the cultured cells. For the understanding of biological function, it is necessary to adjust cell culture systems in a way that resembles the in vivo situation as closely as possible. Therefore, we applied the ALI technique to membrane cultures of the intestinal porcine epithelial cell lines IPEC-1 and IPEC-J2. These porcine intestinal cells are non carcinoma and non transformed cells and act as an outstanding model to study the role of intestinal epithelial barrier, e.g. its genetical and physiological constitution as well as its sensitivity to toxic substances (Pestka and Smolinski 2005; Rothkoetter 2009; Schierack et al. 2006).

The aim of this ALI cell culture study is (1) to achieve a sufficient supply of oxygen to the metabolically active epithelial layer and (2) to investigate the formation of a polarised and differentiated epithelial structure under optimised oxygen supply. The morphological appearance, expression and distribution of the brush border protein villin, the maintenance of intercellular junctions and the capacity of protein digestion and uptake was analysed in intestinal ALI cultures and compared to conventional cultivation methods.

\section{Materials and methods}

\section{Cell culture protocols}

Intestinal porcine epithelial cells, IPEC-1 and IPEC-J2 (Sus scrofa), were cultured as described by Gonzalez-Vallina et al. (1996). In all experiments, cells were seeded with a density of $0.6 \times 10^{5} / \mathrm{mL}$ (IPEC-1) and $0.5 \times 10^{5} / \mathrm{mL}$ (IPEC-J2) under different culture conditions: (a) dish: impermeable plastic dishes (Lumox ${ }^{\mathrm{TM}}$, Sarstedt, Germany), (b) conv: conventional transwell-like culture and (c) ALI: air-liquid interface culture (ThinCerts ${ }^{\mathrm{TM}}$, both $1 \mu \mathrm{m}, 15$ diameter, polyester, Greiner bio-one, Germany). DMEM/HAMs F12 supplemented with $5 \%$ FCS, $5 \mathrm{~mL} /$ $500 \mathrm{~mL}$ cell culture medium ITS, $16 \mathrm{mM}$ HEPES (all PAN, Germany) and $5 \mathrm{ng} / \mathrm{mL}$ EGF (Biochrome, Germany) was used in every experiment as culture medium. Cells grew at $39^{\circ} \mathrm{C}$ in an atmosphere of $5 \% \mathrm{CO}_{2}$ and $95 \%$ relative humidity. If inserts were used as support $1 \mathrm{~mL}$ of medium was added to the upper compartment and $2 \mathrm{~mL}$ to the basal compartment. When cells reached confluence after 10 days $(>1 \mathrm{k} \Omega$, defined as day $-10-0)$ medium from the apical side of the cells was removed for ALI cultivation (defined as day 0), ALI cells were further cultivated for 21 days (defined as day 1-21) and medium on the basal side of the cells was changed every 2 days.

\section{Transepithelial electrical resistance (TEER)} measurement

The TEER value was measured every 7 days using a Millicell-TERS (Millipore, Germany). Pre-equilibrated medium was added to the apical side of the ALI cultures (1 $\mathrm{mL})$ to measure the TEER values. Cultures which were not cultivated as ALI were also checked for TEER values every 7 days.

Epifluorescence and confocal microscopy

IPEC-1 and IPEC-J2 monolayers were fixed with ethanol $(96.8 \%)$ for $30 \mathrm{~min}$ at $4^{\circ} \mathrm{C}$ and with pre-cooled $\left(-20^{\circ} \mathrm{C}\right)$ acetone (all: Roth, Germany) for $3 \mathrm{~min}$. Samples were washed three times with $0.1 \mathrm{M}$ phosphate-buffered saline without $\mathrm{Ca}^{2+}$ and $\mathrm{Mg}^{2+}\left(\mathrm{PBS}^{-}\right)$, blocked with 1:100 normal goat serum (NGS; Axxora, Germany), and incubated with the primary antibodies (rabbit anti-ZO-1, 1:100, Zymed Laboratories, USA and monoclonal mouse antivillin, 1:100, Millipore, Germany). In the next step, 
samples were washed three times and incubated for $1 \mathrm{~h}$ with secondary antibodies (donkey anti-rabbit IgG Alexa 488, 1:200 and goat anti-mouse IgG1 Texas Red, 1:200, both from Invitrogen, Germany), washed and mounted on slides with vectashield (Vector Laboratories, USA). 4',6diamidino-2-phenylindole (DAPI) was used to visualise nuclei (1:10, 5 min, Partec, Germany). Distribution of ZO1 in $x-y$ plane was visualised by epifluorescence microscopy using a Zeiss Axiovert $200 \mathrm{M}$ inverse microscope (Zeiss, Jena, Germany). Villin and internalised dylightBSA structures (see below) were analysed by confocal microscopy using a Leica SP2 confocal microscope (Leica, Heidelberg, Germany). Detection of three-dimensional distributions was visualised after orthogonal projection of the optical sections (ImageJ, NIH). Images shown are representative of at least three experiments, with multiple areas imaged per slide. Different data were processed: (a) ZO-1, localised on the cell border, was used to measure the cell surface. (b) DAPI was used to analyse the number of cells per image and to measure the nucleus size of the cells.

\section{Cell proliferation study using BrdU}

DNA synthesis was detected by $5^{\prime}$-brome-2' $2^{\prime}$-deoxyuridine (BrdU; Roche, Germany) incorporation in conventional membrane and ALI cultivation. Cell cultures were fixed in absolute ethanol at $4^{\circ} \mathrm{C}$ for $30 \mathrm{~min}$ and in acetone for 3 min, detached, washed in Tris-buffered saline (TBS, $0.05 \%$ Tween, $\mathrm{pH} 7.6$ ) and blocked with $1 \%$ normal goat serum (NGS, Axxora, Germany) for $10 \mathrm{~min}$. Cells were treated with $2 \mathrm{M} \mathrm{HCl}$ at $37^{\circ} \mathrm{C}$ for $30 \mathrm{~min}$ and neutralised at room temperature in $0.1 \mathrm{M}$ sodium borate $(\mathrm{pH} 8.5)$ twice for $5 \mathrm{~min}$. After $30 \mathrm{~min}$ at $4^{\circ} \mathrm{C}$ in TBS/Tween $(0.05 \%$ ) cell cultures were incubated with mouse monoclonal anti-BrdU (1:100; BD Pharmingen, USA) for $30 \mathrm{~min}$, with a biotinlabelled goat anti-mouse IgG1 antibody (1:50; Southern biotech, USA) for $30 \mathrm{~min}$ and with $\mathrm{ABC}$-reagent (ABC Elite, Vector Laboratories, USA) for $60 \mathrm{~min}$ at room temperature. Diaminobenzidine solution (DAB, in $0.1 \mathrm{M}$ PBS, freshly added $0.015 \% \mathrm{H}_{2} \mathrm{O}_{2}$ ) was added for $1 \mathrm{~min}$ and cells were subsequently counter-stained with haematoxylin. The immunolabelled (brown) and haematoxylinstained nuclei (blue) were counted manually.

Transmisssion electron microscopy (TEM)

Samples were treated with fixation solution containing $0.5 \%$ paraformaldehyde and $0.5 \%$ glutaraldehyde in $0.1 \mathrm{M}$ phosphate buffer (pH 7.4) over night. After fixation, the dishes, membranes and tissue were washed with phosphate buffer, cut out and kept in phosphate buffer. Subsequently, samples were treated with $1 \%$ osmium tetroxide (Science Services, Munich, Germany) in $0.1 \mathrm{M}$ phosphate buffer.
Samples were rinsed in buffer, dehydrated and bloc-contrasted for $1 \mathrm{~h}$ with $1 \%$ uranyl acetate in $70 \%$ ethanol. Finally, the dishes, membranes and tissue were infiltrated with Durcupan ACM (Fluka, Buchs, Switzerland) and flat embedded between plastic foils. The resin polymerised in an oven at $70^{\circ} \mathrm{C}$ for 2 days. Regions of interest were cut out and glued vertically onto a blank block of resin with a small groove. With an Ultracut S ultramicrotome (Reichert, Leica AG, Vienna, Austria) semithin sections (1 $\mu \mathrm{m})$ were cut and counterstained with toluidine blue for light microscopic measurements on slides. Ultrathin sections (50-70 nm) were collected on Formvar-coated slot grids of copper. They were further contrasted with $2 \%$ uranyl acetate and $0.1 \%$ lead citrate and examined in a LEO $906 \mathrm{E}$ transmission electron microscope of Zeiss (Oberkochen, Germany) equipped with a digital $1 \mathrm{~K}$ BioScan camera (Gatan Inc., Pleasanton, USA).

\section{RNA isolation and Standard PCR}

TRIZOL reagent (Invitrogen) was added to samples of IPEC-1 and IPEC-J2. The cells were scraped off the support and cell suspensions were homogenised with a $21 \mathrm{G}$ syringe (microlance, BD, Germany). In the next step, chloroform was added to the cell suspensions and RNA recovered from the aqueous phase by precipitation with isopropyl alcohol. After drying the pellet was dissolved in DEPC water (Roche) and stored at $-80^{\circ} \mathrm{C}$. Reverse transcription PCR was performed using the RevertAid First Strand cDNA Synthesis Kit (Fermentas, Germany). Reaction conditions and PCR program followed the manufacturer's instructions. Different porcine gene specific primers were used (Table 1). Primer pairs were designed using Primer3 program based on NCBI porcine sequences.

PCR reaction mixtures of $25 \mu \mathrm{L}$ contained 2 pmol primer pairs (MWG, Germany), 50\% FastStart ${ }^{\circledR}$ PCR Master (Roche) and 80 ng cDNA template. PCR amplification was performed under the following conditions: $5 \mathrm{~min}$ of preincubation at $95^{\circ} \mathrm{C}$, followed by 35 thermal cycles of $30 \mathrm{~s}$ denaturation at $95^{\circ} \mathrm{C}, 30 \mathrm{~s}$ primer annealing at $55^{\circ} \mathrm{C}$ and $45 \mathrm{~s}$ extension at $72^{\circ} \mathrm{C}$. A final elongation step was performed at $72^{\circ} \mathrm{C}$ for $10 \mathrm{~min}$ (Eppendorf Mastercycler gradient, Germany). Aliquots of $10 \mu \mathrm{L}$ of PCR products were identified through gel electrophoresis on a $0.2 \mu \mathrm{g} / \mathrm{mL}$ ethidium bromide stained 1\% agarose gel (MassRuler ${ }^{\circledR}$ DNA Ladder low range, Fermentas, Germany). Agarose gels were analysed with Alpha-Ease ${ }^{\circledR}$ FC Imaging System (Alpha Innotech, Canada).

\section{qRT-PCR}

For the qRT-PCR the efficiency of each primer (Table 1) was tested. The best efficiency was found at $54^{\circ} \mathrm{C}$ 
Table 1 Defined porcine primers for PCR and qRT-PCR

\begin{tabular}{|c|c|c|c|}
\hline Gene & Abbr. & Sequence & PCR product (bp) \\
\hline \multirow[t]{2}{*}{ Glyceraldehyde3-phosphate dehydrogenase } & GAPDH-f & $5^{\prime}$-ttccacggcacagtcaa & \multirow[t]{2}{*}{576} \\
\hline & GAPDH-r & $5^{\prime}$-gcaggtcaggtccacaa & \\
\hline \multirow[t]{2}{*}{ Beta-Actin (qRT-PCR) } & $\beta$-actin-f & $5^{\prime}$-gatgagattggcatggcttt & \multirow[t]{2}{*}{122} \\
\hline & $\beta$-actin-r & $5^{\prime}$-caccttcaccgttccagttt & \\
\hline \multirow[t]{2}{*}{ Occludin } & Occludin-f & $5^{\prime}$-gacgagctggaggaagactg & \multirow[t]{2}{*}{319} \\
\hline & Occludin-r & $5^{\prime}$-ctccaaccatcttcttgatgtg & \\
\hline \multirow[t]{2}{*}{$\mathrm{ZO}-1$} & $\mathrm{ZO}-1 \mathrm{~b}-\mathrm{f}$ & $5^{\prime}$-ccgectcctgagtttgatag & \multirow[t]{2}{*}{251} \\
\hline & ZO-1b-r & $5^{\prime}$-tcaggaatagctccetgtgg & \\
\hline \multirow[t]{2}{*}{ Sodium-dependent glucose cotransporter 1} & SGLT1-f & $5^{\prime}$-acatctgtctgggctggaac & \multirow[t]{2}{*}{705} \\
\hline & SGLT1-r & $5^{\prime}$-agacgtccatggtgaagagg & \\
\hline \multirow[t]{2}{*}{ Villin-1 (qRT-PCR) } & Vil-1-f & $5^{\prime}$-caccatgaccaaactgaacg & \multirow[t]{2}{*}{129} \\
\hline & Vil-1-r & $5^{\prime}$-tcgaagaagctgccataggt & \\
\hline \multirow[t]{2}{*}{ Cytokeratin 18} & Ck18-f & $5^{\prime}$-aaggcctacaagcccagatt & \multirow[t]{2}{*}{644} \\
\hline & Ck18-r & $5^{\prime}$-cctgcttctgctggcttaat & \\
\hline \multirow[t]{2}{*}{ Mucin 1} & Muc1-f & $5^{\prime}$-gaagatcccaccaccagcta & \multirow[t]{2}{*}{594} \\
\hline & Muc1-r & $5^{\prime}$-actgtcttggaaggccagaa & \\
\hline
\end{tabular}

$(\beta$-actin $=96.7 \%$ and Vil- $1=94 \%)$. PCR reaction mixtures of $25 \mu \mathrm{L}$ contained 3 pmol Vil-1-forward, 6 pmol $\beta$ actin-forward, 9 pmol of Vil-1-reverse, 3 pmol $\beta$-actinreverse, $50 \%$ qRT-PCR Maxima ${ }^{\mathrm{TM}}$ SYBR GREEN qPCR Master Mix $(2 \times)$ (Fermentas, USA) and $60 \mathrm{ng}$ cDNA template. PCR amplification was performed under the following conditions: $5 \mathrm{~min}$ of preincubation at $95^{\circ} \mathrm{C}$, followed by 40 thermal cycles of $30 \mathrm{~s}$ denaturation at $95^{\circ} \mathrm{C}$, $60 \mathrm{~s}$ of annealing and extension at $54^{\circ} \mathrm{C}$ (iCycler, BIORAD, Germany). The analysis consisted of at least five independent experiments. Each experimental sample was assayed using three replicates for each primer. The $\Delta \Delta C_{\mathrm{t}^{-}}$ method was used for the calculation of the differences in the expression profiles. The relative difference of the expression of a sample between treatment and control, which were normalised to the reference gene, $\beta$-actin, and based on a standard probe, resulted in the set phrase: ratio $=2^{-\Delta \Delta C_{\mathrm{t}}}$. In this study, cells which were stored for 3 days in the refrigerator to assure the degradation of villin-mRNA were used as calibrator.

\section{Western blot}

Cell homogenate protein was incubated for $10 \mathrm{~min}$ with SDS-gel loading buffer (1 M Tris base, $\mathrm{pH} 6.8 ; 1 \%$ Glycerol; $10 \%$ SDS; $0.1 \%$ Bromophenol blue; freshly added with $0.05 \% \quad \beta$-mercaptoethanol and $1 \%$ protease inhibitors; Complete, Roche). Afterwards, cultured cells were scraped with a cell scraper off the dish or membrane. Samples were denatured at $95^{\circ} \mathrm{C}$ for $5 \mathrm{~min}$. In the next step, probes were loaded together with the prestained protein ladder (SM 1811; Fermentas, Germany) onto a $10 \%$ SDS-polyacrylamide gel. After electrophoresis and semidry blotting onto $0.45-\mu \mathrm{m}$ nitrocellulose membranes (Whatman, Germany) primary mouse anti-villin antibody (1:1,000; Invitrogen) were used in blocking reagent. The secondary antibody was purchased with the "BM Chemiluminescence Western Blotting Kit mouse/rabbit" (Roche). Afterwards, the blots were stripped at $50^{\circ} \mathrm{C}$ for $30 \mathrm{~min}$ with stripping buffer (7.6 g Tris base, $20 \mathrm{~g}$ SDS, $7 \mathrm{~mL} \beta$ mercaptoethanol, $\mathrm{pH} 6.8$ ), washed and re-probed with antiGAPDH antibody (1:1,000, Cell Signaling, Germany). Blots were analysed on an Alpha-Ease ${ }^{\circledR}$ FC Imaging System (Alpha Innotech).

\section{Uptake of BSA-DyLight}

Cells were seeded under different conditions as described before: (a) on inserts and (b) as ALI culture (both 24-wellThinCerts $^{\mathrm{TM}}, 1-\mu \mathrm{m}$ pore size, polyester, Greiner bio-one, Germany). After 10 days of cultivation, when cells reached confluence, medium was changed every 2 days stepwise from $5 \%$ FCS, $2.5 \%$ FCS to $1 \%$ FCS. 2 days later, medium from the apical side of the cells was removed (defined day 0 ) for 21 days and medium on the basal side of the cells was changed to FCS-free medium. After 21 days of cultivation, $50 \mu \mathrm{L}$ BSA-DyLight Texas Red 594 (Pierce, USA) was added to the apical side and $200 \mu \mathrm{L}$ fresh FCS-free medium to the basal side. Cultured cells were incubated for $24 \mathrm{~h}$ with BSA-DyLight at $39^{\circ} \mathrm{C}$ in an atmosphere of $5 \%$ $\mathrm{CO}_{2}$. In the next step, cells were washed, fixed and stained with DAPI as described before. BSA-DyLight was made 
following the manufacturer's instructions and is stable at pH 4-9. HBSS (Biochrom, Germany) supplemented with $\mathrm{Ca}^{2+}$ and $\mathrm{Mg}^{2+}$ was used as dialysis-medium.

\section{Statistical analysis}

Results are expressed as means and S.E.M. of at least three separate experiments. Analyses were performed with ANOVA (SPSS 17) and Dunnett's post test. Asterisks indicate significant differences from control $\left({ }^{*} p \leq 0.05\right.$; $* * p \leq 0.01 ; * * * \leq 0.001)$.

\section{Results}

Morphological analysis of the epithelial cell layer

We compared IPEC-1 and IPEC-J2 cells cultured on an impermeable surface (dish), conventional transwell-like membrane cultures (conv) and membrane cultures handled according to the air-liquid interface (ALI) protocol. Cell layers were fixed and the morphology was analysed by immunofluorescence and TEM. Representative examples of immunofluorescence staining of the tight junction protein ZO-1 and TEM pictures are shown in Figs. 1 and 2. The quantitative analysis of morphological parameters is given in Table 2 and data are visualized in Fig. 3. The ultrastructure of IPEC-1 and IPEC-J2 is shown in Fig. 2. Membranes are visible beneath the cells as more or less structured compartment. Being cultured on impermeable support both cell lines (Fig. 2a, b) showed a sustained and flat phenotype (monolayer) with an oval nucleus. For both cell lines an increased thickness of their layer was visible on conventional membrane cultures (Fig. 2c, d) and cultured as ALI (Fig. 2e, f). A "bubble-like" phenotype (Fig. 2e) was only noticed in IPEC-1 cells, which also present thicker layers. For comparison with the in vivo situation a fixed jejunum (Fig. 2g) is shown with long and dense microvilli. The method of cultivation of IPEC-1 and IPEC-J2 cells had obviously a detrimental effect on the morphological appearance of the cultured cells. We detected a significant decrease of the cell surface in both cell lines in the order dish culture $>$ conventional membrane culture $>$ ALI culture (Table 2, cell area). In parallel, the thickness of the cellular layer increased significantly in the same manner (Table 2, layer thickness). In case of IPEC-1 cultured according to the ALI protocol the cell shape resembled the cell shape calculated for the in vivo situation (Fig. 3, in vivo and Table 2, intestine). We noticed also a significant increase of the cell number per area $\left(10,000 \mu \mathrm{m}^{2}\right)$ and a significant decrease of the nucleus area in both cell lines. The data were used to calculate the theoretical cell volumes. Further, we calculated an increase of the cell volume in both cell lines in the order dish culture $<$ conventional membrane culture $<$ ALI culture. The theoretical cell volume of ALI cultures was similar to that calculated for intestinal epithelial cells in vivo (Table 2). In addition, we observed a continuous linear distribution of tight junction protein ZO-1 along the apical side of cell-cell contacts (Fig. 1a-c). In IPEC-1, cells cultured according to the ALI protocol, this pattern was similar to the in vivo pattern of flat slices of the porcine intestine (Fig. 1d, e). Furthermore using TEM, we analysed the structure of epithelial tight junctions and microvilli. Electron micrographs show morphological details like microvilli (Fig. 4a, b) and tight junctions (Fig. 4c, d) for IPEC-1 (Fig. 4a, c) and IPEC-J2 (Fig. 4b, d). Both cell lines presented microvilli but those of IPEC-1 were less and smaller. This was evident for all culturing methods and exemplary shown here for the impermeable support. The appearance of tight junctions at the apical surface of the cells was similar for all culturing methods and is shown here exemplary for membranes.

Integrity of epithelial cell layer measured by TEER

IPEC-1 and IPEC-J2 cultured conventionally on membrane or according to the ALI protocol were accessible for measurements of TEER (Fig. 5). During conventional cultivation up to 10 days (day -10-0) TEER increased to approximately $2-3 \mathrm{k} \Omega / \mathrm{cm}^{2}$ in IPEC- 1 (Fig. 5a). The TEER of IPEC-J2 cells was lower (around $1 \mathrm{k} \Omega / \mathrm{cm}^{2}$ ) at day 0 in comparison to IPEC-1 (Fig. 5b). Between day 0 (IPEC-1)/ day 7 (IPEC-J2) and day 21 the TEER was above $1 \mathrm{k} \Omega / \mathrm{cm}^{2}$ independent of the mode of culture method and remained essentially stable.

Proliferation analysis in conventional membrane and ALI cultures

Proliferation of IPEC-1 and IPEC-J2 cells was quantified by detection of BrdU incorporation on single cell level. A significant reduction of proliferating cells was detected between dish and membrane cultures and between dish and ALI cultures in IPEC-1 (Fig. 6a). However, no significant difference between conventional membrane culture and ALI conditions was found with IPEC-J2 cells (Fig. 6b). Remarkably, IPEC-J2 cells exhibited an already significant lower degree of BrdU uptake in comparison to IPEC-1 cells independent of the culture method.

Expression of IPEC-1 and IPEC-J2 mRNA in different cultivation methods

The mRNA expressions of epithelial marker proteins were tested using standard RT-PCR. Specific mRNA signals were found for GAPDH, $\beta$-actin, Ck18, ZO-1, occludin and 
Fig. 1 Influence of cell culture method on morphology and expression of tight junction protein ZO-1 in intestinal porcine epithelial cell lines IPEC-1 and IPEC-J2.

Immunfluorescence staining of cells cultured on

(a) impermeable dish (dish),

(b) porous membrane $(1-\mu \mathrm{m}$ pore size) applying a

conventional culture procedure (conv) and (c) porous membrane applying air-liquidinterface (ALI) culture conditions with enriched access to oxygen. d Section of porcine intestinal mucosa showing ZO-1 distribution in three villi in $x-y$ layer (flat section villus 1 , arrow) and in $z-y$ layer (villus II and III, cross-section, arrowhead). e Low magnification scheme of section d. Scale bar $20 \mu \mathrm{m}$
IPEC-1
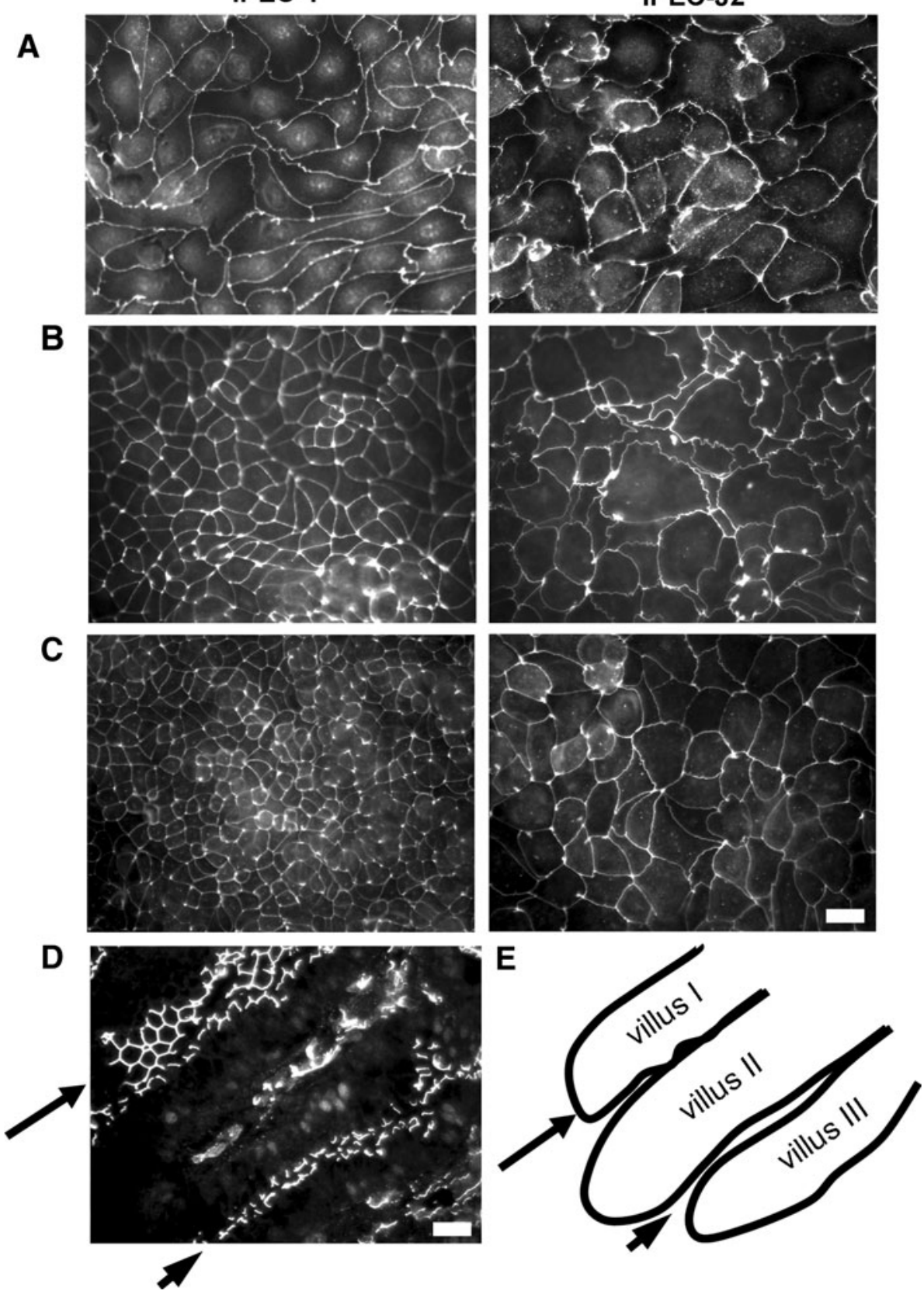

Muc1, independent of the mode of cultivation. Remarkably, mRNA of the brush border protein villin was absent in IPEC-1 cells cultured in the dish culture in standard RTPCR (results not shown). The difference of villin mRNA levels were quantitatively analysed in qRT-PCR (Fig. 7). In IPEC-1, we detected a significant increase of villin mRNA level in conventional membrane and ALI cultures in comparison to dishes cultures. In parallel, the amount of villin mRNA was also significantly increased in IPEC-J2 cells cultured conventionally on membranes in comparison to impermeable dish cultures. However, ALI cultures of
IPEC-J2 cells did not show a significant enhanced villin mRNA level in comparison to dish culture.

Protein expression and distribution of the brush border marker villin

Furthermore, we analysed the protein expression and the intracellular localisation of villin in the investigated cell lines and cell culture modes. As shown in Fig. 8, the amount of villin was generally lower in IPEC-1 than in IPEC-J2. Moreover, only IPEC-1 cells cultured in the ALI 

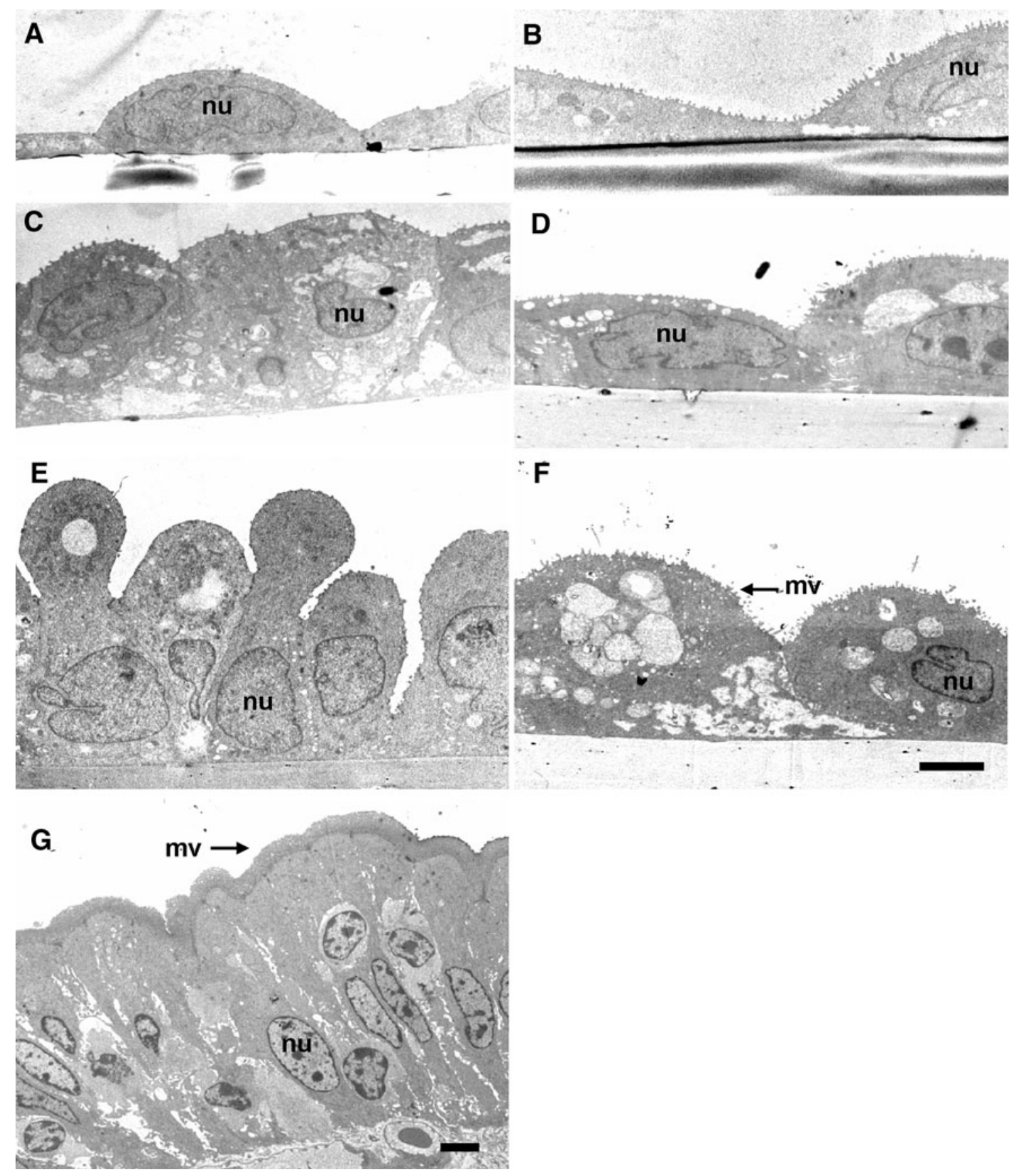

Fig. 2 Ultrastructural analysis of IPEC-1 and IPEC-J2 cell lines cultured with different supports and conditions. IPEC-1 cells (a, c, e) and IPEC-J2 cells (b, d, f) were cultured conventionally on impermeable support (a, b), on $1 \mu \mathrm{m}$ membrane (c, d) and according to the ALI protocol on $1 \mu \mathrm{m}$ membrane $(\mathbf{e}, \mathbf{f})$. A section of porcine jejunum is shown for comparison (g). Apical side of the cell layer is on the top. Microvilli structures (mv) are located on apical membrane $(\mathbf{e}-\mathbf{g})$ and basolateral intercellular spaces are shown $(\mathbf{c}-\mathbf{g})$. Nucleus (nu). Scale bar $4 \mu \mathrm{m}(\mathbf{a}-\mathbf{f})$

the $z$-dimension of the cell layer (Fig. 9). In conventional membrane cultures, villin was homogenously distributed in the cytosol without detectable colocalisation with any subcellular structure (Fig. 9a). In contrast, ALI cultured IPEC-J2 cells exhibited at least partially a prominent localisation of villin at the apical pole of the cell layer mode showed a minimal but detectable amount of villin protein. IPEC-J2 cells expressed comparable amounts of villin in all cultivation modes. The cellular localisation of villin in IPEC-J2 cells was visualised by immunofluorescence staining and confocal microscopy, allowing the localisation of immunofluorescense stained structures in 
Table 2 Comparison of morphological parameters of IPEC cells grown under different culture conditions to in vivo situation

\begin{tabular}{|c|c|c|c|c|}
\hline & Dish & Conv & ALI & Intestine \\
\hline \multicolumn{5}{|l|}{ IPEC-1 } \\
\hline Number nuclei/10,000 $\mu \mathrm{m}^{2}$ & $16.98 \pm 2.41^{\mathrm{a}}$ & $58.8 \pm 10.31^{\mathrm{ab}}$ & $109.01 \pm 21.97^{\mathrm{bc}}$ & $169.76 \pm 73.81^{\mathrm{c}}$ \\
\hline Nuclei area $\left(\mu \mathrm{m}^{2}\right)$ & $122.05 \pm 24.33^{\mathrm{a}}$ & $70.65 \pm 16.09^{\mathrm{b}}$ & $39.93 \pm 9.33^{c}$ & $39.94 \pm 10.69^{\mathrm{d}}$ \\
\hline Cell area $\left(\mu \mathrm{m}^{2}\right)$ & $683.35 \pm 571.36^{\mathrm{a}}$ & $172.54 \pm 56.99^{\mathrm{b}}$ & $72.91 \pm 25.43^{\mathrm{c}}$ & $55.1 \pm 25.44^{\mathrm{c}}$ \\
\hline Layer thickness $(\mu \mathrm{m})$ & $3.75 \pm 2.15^{\mathrm{a}}$ & $10.54 \pm 2.69^{\mathrm{b}}$ & $17.41 \pm 5.07^{\mathrm{c}}$ & $23.67 \pm 3.96^{\mathrm{d}}$ \\
\hline Hypothetical cell volume $\left(\mu \mathrm{m}^{3}\right)$ & 324.34 & 490.80 & 527 & 622.86 \\
\hline \multicolumn{5}{|l|}{ IPEC-J2 } \\
\hline Number nuclei/10,000 $\mu \mathrm{m}^{2}$ & $8.58 \pm 2.54^{\mathrm{a}}$ & $16.19 \pm 2.63^{\mathrm{a}}$ & $24.67 \pm 6.04^{\mathrm{a}}$ & 146. $29 \pm 79.31^{\mathrm{b}}$ \\
\hline Nuclei area $\left(\mu \mathrm{m}^{2}\right)$ & $167.5 \pm 52.8^{\mathrm{a}}$ & $143.15 \pm 40.34^{\mathrm{b}}$ & $117.26 \pm 26^{\mathrm{c}}$ & $39.52 \pm 11.44^{\mathrm{d}}$ \\
\hline Cell area $\left(\mu \mathrm{m}^{2}\right)$ & $1309.84 \pm 774.75^{\mathrm{a}}$ & $587.83 \pm 325.3^{\mathrm{b}}$ & $461.59 \pm 212.39^{c}$ & $56.63 \pm 26.41^{\mathrm{d}}$ \\
\hline Layer thickness $(\mu \mathrm{m})$ & $3.47 \pm 2.27^{\mathrm{a}}$ & $7.31 \pm 2.44^{\mathrm{b}}$ & $8.09 \pm 2.98^{\mathrm{c}}$ & $23.24 \pm 3.91^{\mathrm{d}}$ \\
\hline Hypothetical cell volume $\left(\mu \mathrm{m}^{3}\right)$ & 445.2 & 628.17 & 616.15 & 619.98 \\
\hline
\end{tabular}

The measured cell surface was used to calculate the average radius of the cells. The circle was chosen as basic form. The hypothetical volume of the cells was calculated via the average radius and the height of the monolayer. Therefore, the cylinder was used as basic shape $\left(V=\pi r^{2} h\right)$. Groups with identical letters were not significantly different $(\boldsymbol{p}>0.05)$

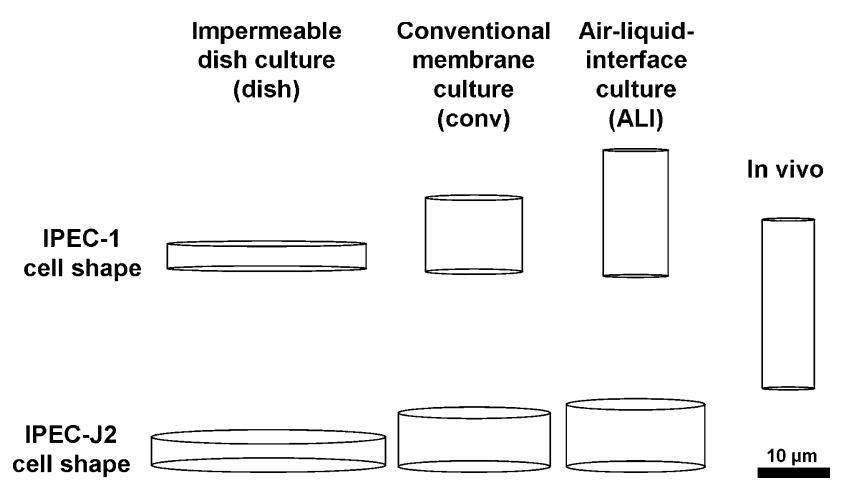

Fig. 3 Visualization of geometric parameters of IPEC-1 and IPEC-J2 cells as a function of cell culture condition. IPEC-1 and IPEC-J2 cells were cultured under different cell culture conditions as indicated. Average cell diameter and cell thickness were used to calculate a hypothetical cell volume representing characteristic cell shape under the given culture condition. Scale bar $10 \mu \mathrm{m}$

(Fig. 9b). The red rims visible in Fig. 9b not in relation to blue nuclei indicating the enrichment of villin on membrane areas with nuclei out of focus.

Functional analysis of protein handling in conventional membrane and ALI cultures

In the next step, we analysed the uptake capacity of IPEC-1 and IPEC-J2 cells for fluorescence-labelled proteins and peptides for a functional analysis of the cell culture conditions. Fluorescence-labelled bovine serum albumin (BSA) was applied onto the apical cell surface of conventional membrane and ALI cultures. The fate of the model protein was monitored by confocal microscopy $24 \mathrm{~h}$ after application. As shown in Fig. 10, in conventional membrane cultures the condensed red fluorescence-labelled protein was visible on the apical surface of IPEC-1 (Fig. 10a) and IPEC-J2 (Fig. 10c) cells $24 \mathrm{~h}$ after application. The non-stained area around the blue DAPI-labelled nuclei indicates cytosolic areas which were nearly free of BSA related staining. In contrast, IPEC-1 (Fig. 10b) and IPEC-J2 (Fig. 10d) cells cultured according to the ALI mode exhibit a clearly cytosolic BSA-related fluorescence indicating a cytosolic transport of the labelled protein structures.

\section{Discussion}

It is known that the selection of the culture conditions has a tremendous effect on the morphology and function of epithelial cells in vitro. As an example, gastric surface mucous cells (GSM06) develop a characteristic columnar cell shape with an apical mucous layer accompanied by further epithelial differentiation markers when cultured in ALI culture conditions (Ootani et al. 2000; Yokoyama et al. 2007). The major physical parameter affected by the ALI culture method is for sure the improved oxygen supply. Obviously, the ALI cell culture model mimics the in vivo conditions in the stomach better than conventional membrane or conventional dish culture despite the fact that the improved oxygen supply affects the cell layer on the apical side, which is in contrast to the in vivo situation. However, as oxygen enters the cell via diffusion this misfit of the model is marginal with respect to the epithelial cell physiology (Taylor and Colgan 2007). Mucosal epithelial cells depend on sufficient oxygen supply by the mucosal microvascular circulation in vivo (Sinaasappel et al. 1999). 


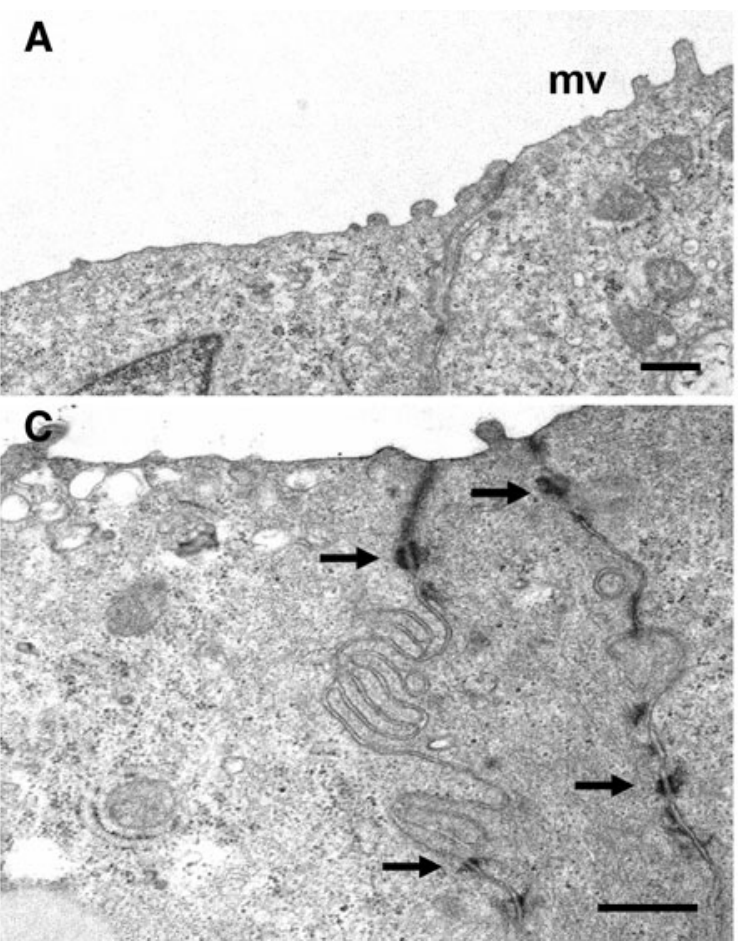

Fig. 4 Ultrastructural view of apical side of membrane cultured IPEC-1 and IPEC-J2 cells. Electron microscopical analysis of apical side of cultured intestinal cell lines exhibit low degree of microvilli (mv) in IPEC-1 cells (a) in comparison to IPEC-J2 cells (b).
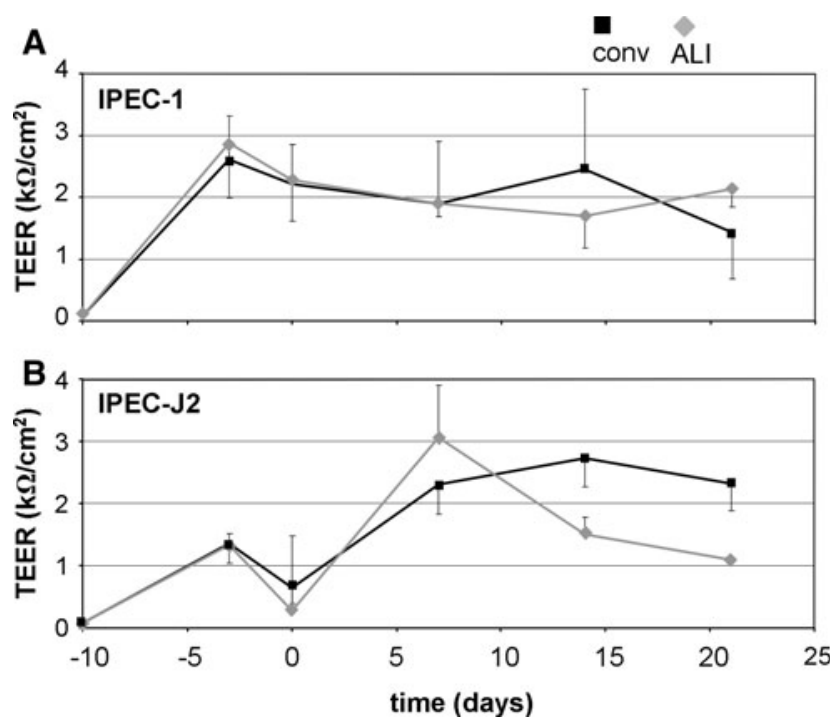

Fig. 5 TEER measurement of IPEC-1 and IPEC-J2 cells cultured on conventional membrane and as ALI system. IPEC-1 (a) and IPEC-J2 (b) cells were seeded (day -10$)$ on cell culture inserts with $1-\mu \mathrm{m}$ pore size (12-well format) and TEER was regularly monitored (TEER $\mathrm{k} \Omega$ / $\mathrm{cm}^{2}$ and SEM.). At day 0 cultures were switched to ALI culture mode (ALI) or were further handled conventionally (conv). IPEC-1 (a) cells formed cell layers with TEER $>1 \mathrm{k} \Omega / \mathrm{cm}^{2}$ at day 0 and maintained the electrical dense structure throughout the cultivation. IPEC-J2 (b) cell layers were around $1 \mathrm{k} \Omega / \mathrm{cm}^{2}$ at day 0 , but exceeded this value during the following cultivation

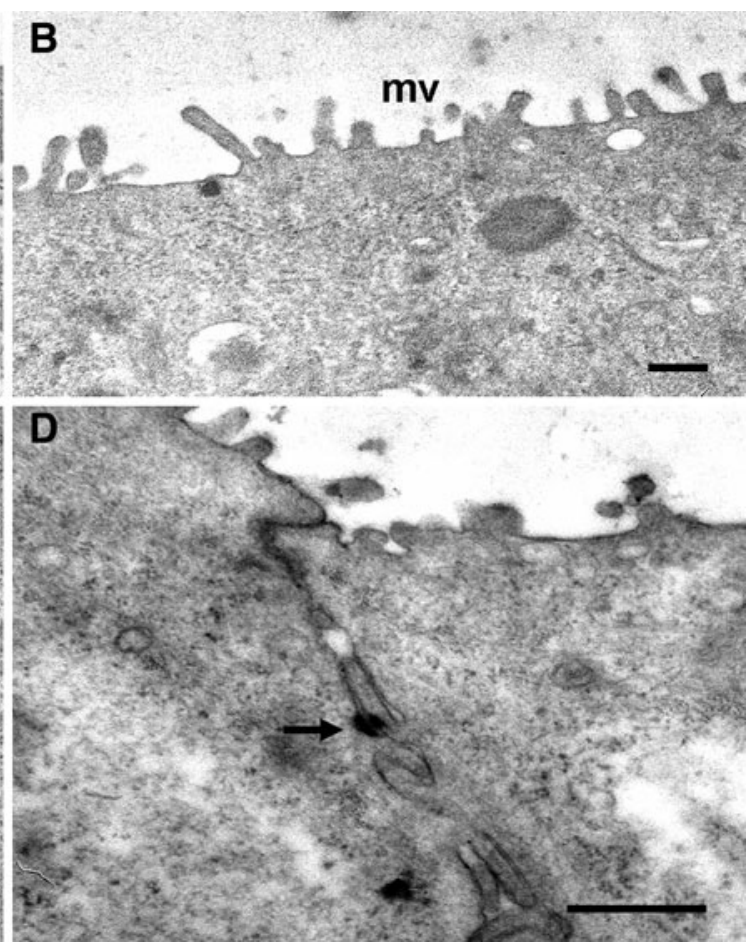

Characteristic tight junction structures (arrows) between adjacent cells were found under all culture conditions in IPEC-1 (c) and IPEC$\mathrm{J} 2$ (d) cells. Scale bar $0.5 \mu \mathrm{m}$

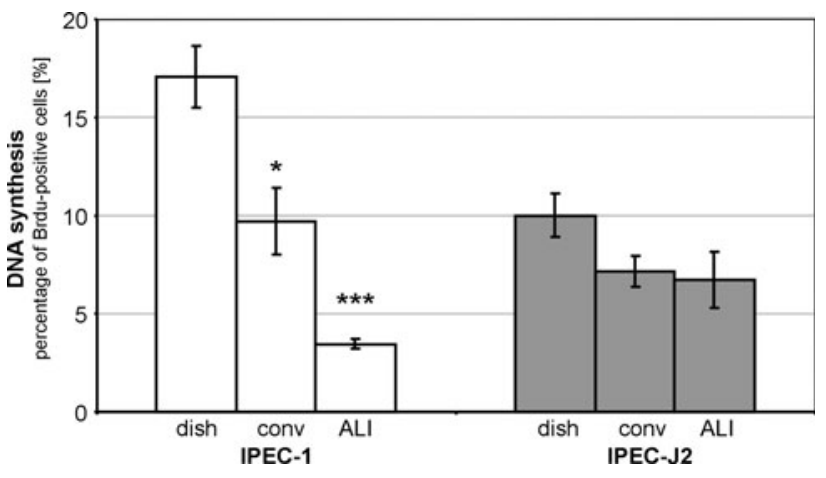

Fig. 6 DNA synthesis of IPEC-1 and IPEC-J2 cells cultured on dish, on conventional membrane and as ALI system. Proliferation of IPEC1 and IPEC-J2 cells was quantified by detection of BrdU incorporation on single cell level. Percentage of BrdU-positive cell nuclei were estimated on dish, membrane (conv) and ALI cultures. Percentage was calculated from at least three independent experiments \pm S.E.M. Significant changes are indicated as ${ }^{*} p \leq 0.01$ and $* * * p \leq 0.001$ versus cells cultured on dish

It has been further shown that the lack of energy in form of ATP depletion disturbs the cellular distribution and localisation of a distinct set of proteins whereas others were obviously insensitive (Bacallao et al. 1994; Mandel et al. 1993, 1994). Taken together, these findings raised the question of the role of oxygen supply in the intestinal cell culture in vitro. 


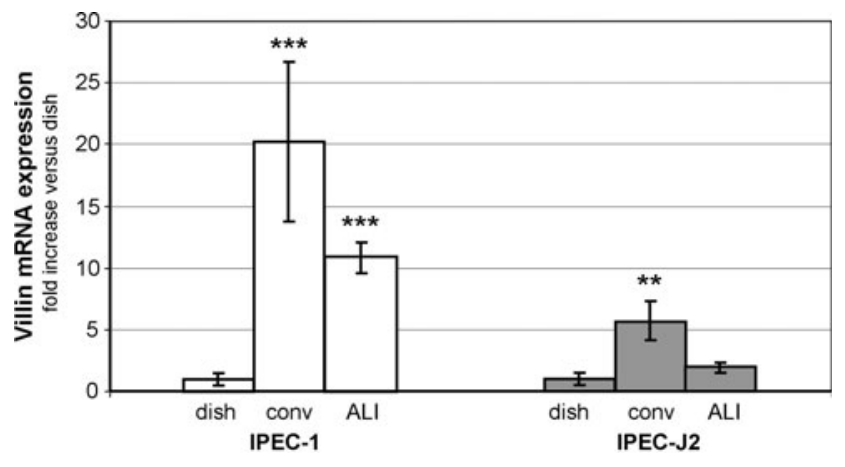

Fig. 7 Comparison of villin mRNA of IPEC-1 and IPEC-J2 cells cultured on dish, on conventional membrane or as ALI system. IPEC1 and IPEC-J2 cells were cultured for 21 days on impermeable surface (dish) and on $1 \mu \mathrm{m}$ membrane in conventional (conv) or ALI (ALI) mode. Levels of mRNA of villin were detected by qRT-PCR and related to mRNA levels detected in corresponding dish culture. Membrane and ALI cultures significantly increased villin mRNA level in IPEC-1. In IPEC-J2 conventional membrane culture significantly increased villin mRNA level, but ALI mode was without significant effect. Increase of mRNA level of villin was calculated from at least six independent experiments \pm S.E.M. Significant changes in ratio in comparison to lowest mRNA level are indicated as ${ }^{* *} p \leq 0.01$ and ${ }^{* * *} p \leq 0.001$ versus cells cultured on dish

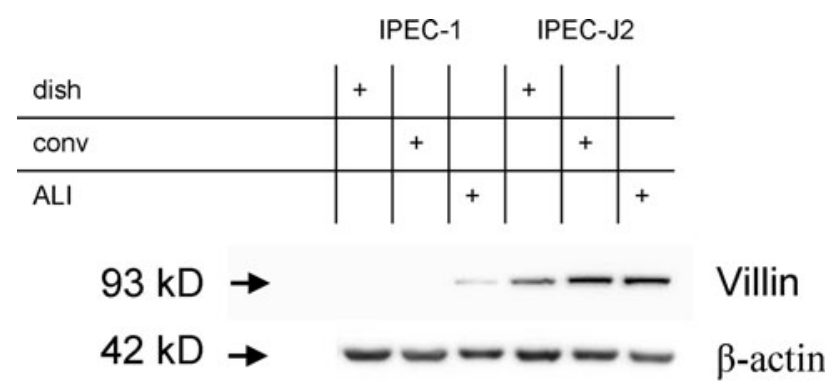

Fig. 8 Comparison of villin protein expression in IPEC-1 and IPEC$\mathrm{J} 2$ cells cultured on dish, on conventional membrane or as ALI system. IPEC-1 and IPEC-J2 cells were cultured for 21 days on impermeable surface (dish) and on $1 \mu \mathrm{m}$ membrane in conventional or ALI mode. Levels of villin protein were detected by western blotting using mouse monoclonal anti-villin antibody and chemoluminescence detection. GAPDH was used as a loading control. In IPEC-1 villin was detectable in membrane cultures of the ALI mode only. IPEC-J2 expressed villin protein in all culture modes with slight enhanced protein levels in membrane and ALI cultures

The elongated and flat cell phenotype with a small cell volume and large nucleus of IPEC-1 and IPEC-J2 cells cultured on conventional dishes and membranes was already reported by Schierack et al. (2006) and GonzalezVallina et al. (1996). We were able to show that IPEC-1 and IPEC-J2 have the typical differentiation of an enterocyte, independent of the culture system. This was demonstrated by (a) the presence of the tight junction protein ZO-1 through immunofluorescence and electron microscopy, (b) the presence of the brush border marker villin and (c) the existence of basolateral intercellular spaces between the epithelial cells and the formation of microvilli structures. However, in our study we were able to show a more specific enterocyte differentiation depending on the culture system (dishes/conv. membranes/ALI cultures). This became evident by (a) the morphological analysis of the epithelial cells, (b) the restricted location of brush border markers, (c) the loss of progeny of differentiated cells and finally, (d) functional protein transport analysis. Thus, the present study demonstrated for the first time that ALI cultivation promotes the specific differentiation and the functional morphology of two intestinal epithelial cell lines obviously due to an improved oxygen supply.

There are two morphological characteristics of the differentiated intestinal epithelium. One is the polarised organisation of intestinal cells on a basement membrane and the other is the columnar shape of the cells with microvilli at the apical membrane (Cheng and Leblond 1974). In our study, we observed an increasing columnar shape, a decreased nucleus size and an increased cell volume in the following order of cell culture methods: conventional dishes, membranes and ALI culture.

The differentiation of epithelial cells in cell culture is influenced by cell density, extracellular matrix, galactose/ glucose substitution or TGF- $\beta$ (Barnard and Warwick 1993; Basson et al. 1996; Kurokowa et al. 1987). For instance, Caco-2, a tumour-derived cell line, forms a polarised monolayer with apical tight junctions and microvilli when the cells reach confluence after a culture of 4 weeks (Halleux and Schneider 1991). In Caco-2 cells the cell-cell contact is the critical step, which resulted in cell cycle exit and the induction of the differentiation process (Deschenes et al. 2001). Our study supports these results, because a significant reduction of proliferating cells was detected in IPEC-1 in the order of dishes $>$ conv. membranes $>$ ALI culture. In IPEC-J2, a marked reduction of cell proliferation in membrane cultures was observed in comparison to the dish cultures. You et al. (2002) showed corresponding results in primary mouse tracheal epithelial cells (MTEC) cells. In their study, they detected a proliferating phase during the first 7-10 days of ALI culture. After this proliferating period, the BrdU incorporation was $<2 \%$, which resulted in the differentiation of the MTEC cells. As a result, they observed a greater number of cultivated cells associated with the differentiation and lower proliferation rate at the end of ALI cultivation (You et al. 2002). Our study also provides evidence for an oxygen supply triggered two phase culture kinetic: initial proliferation and sequential differentiation of intestinal epithelial cells associated with the loss of progeny.

In vivo, enterocyte differentiation occurs along the crypt-villus axis and is thought to be regulated through the transcriptional activation of cell-specific genes like the 


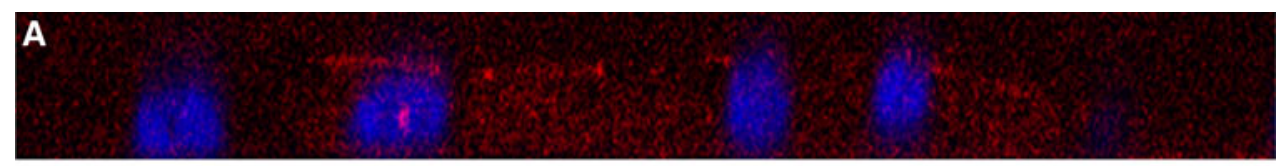

\section{conv}

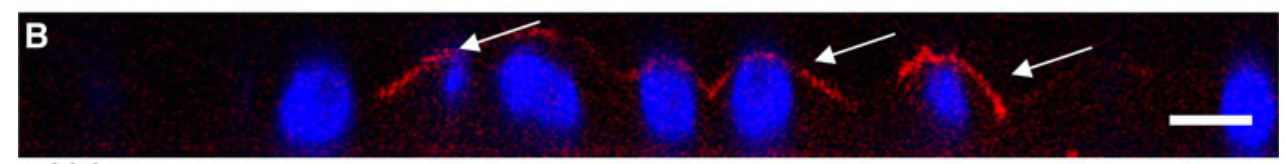

\section{ALI}

Fig. 9 Comparison of villin protein expression in IPEC-J2 cells cultured on conventional membrane or as ALI system. IPEC-J2 cells were cultured on $1 \mu \mathrm{m}$ membranes in conventional (a) and ALI culture mode (b). Villin was detected by immunfluorescence staining and distribution was visualized by confocal microscopy. Figures represent optical sections obtained after three-dimensional reconstructions. In the conventional culture mode, villin is detectable but homogenously distributed in the cell (a). In the ALI culture mode villin is localised at the apical pole of the plasma membrane (b arrows). A representative view is shown. Scale bar $5 \mu \mathrm{m}$
Fig. 10 Uptake of structures in IPEC-1 and IPEC$\mathrm{J} 2$ cell cultured on conventional membrane or as ALI system. IPEC-1 (a, b) and IPEC-J2 (c, d) cells were cultured on $1 \mu \mathrm{m}$ membranes in conventional (a, c) and ALI culture mode $(\mathbf{b}, \mathbf{d})$. DyLight-labelled protein (BSA) was applied apically and confocal microscopy of fixed cells was done after $24 \mathrm{~h}$. Figures represent orthogonal views obtained after threeThe membrane is localised basal of the nuclei. Fluorescence signal was found on the apical border of conventional cultures (a, c) only. ALI cultured cells fluorescence (b, d). Scale bar $5 \mu \mathrm{m}$ fluorescence-labelled BSA dimensional reconstructions. exhibit intracellular

\section{IPEC-1}

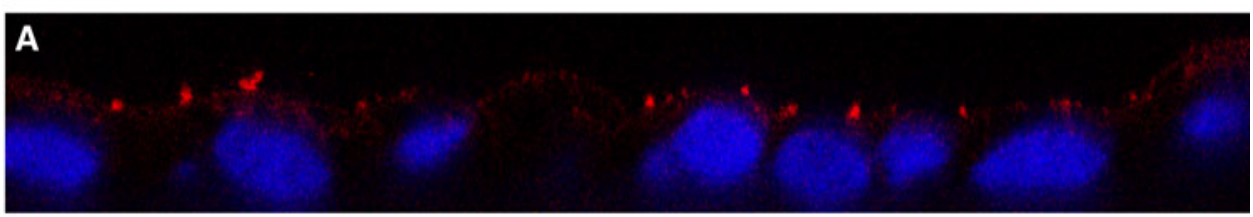

conv

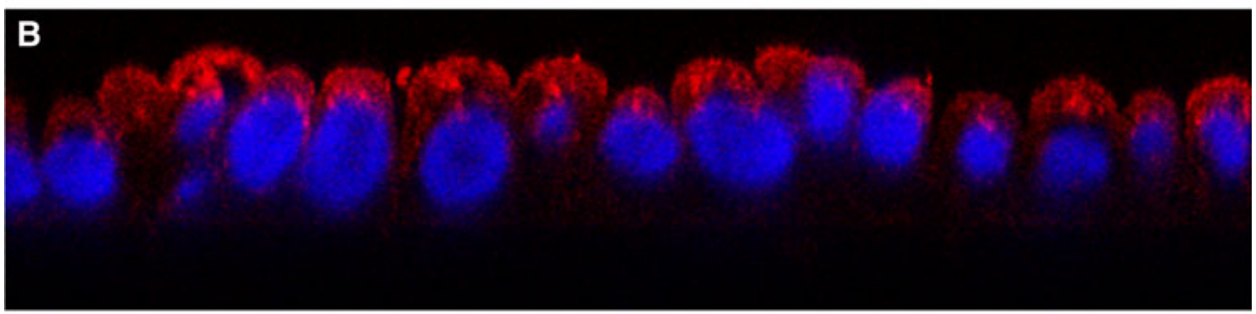

ALI

IPEC-J2

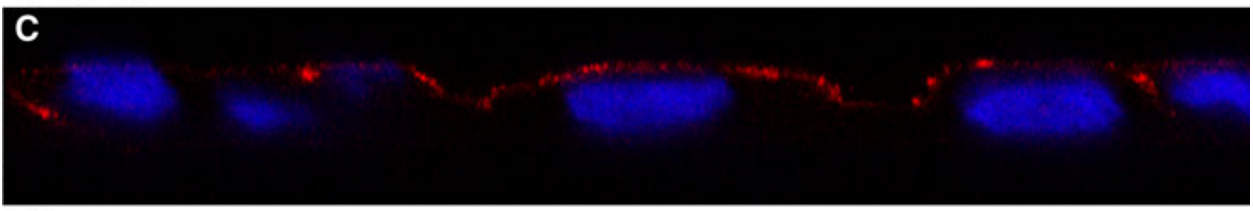

conv

D

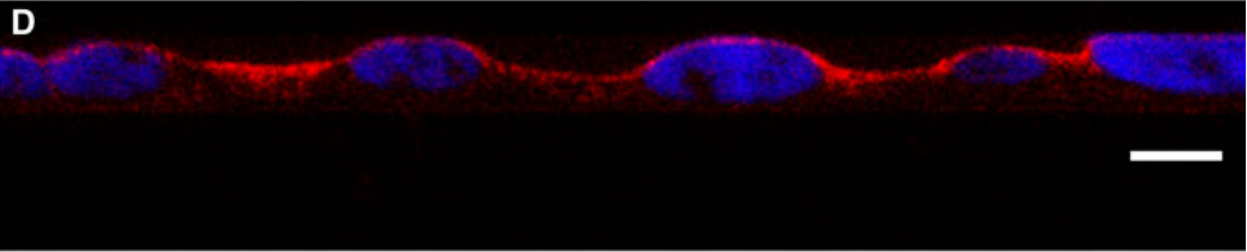

ALI

structural brush border protein villin (Hodin et al. 1997), which is supported by an increased mRNA-level in our membrane cultured cells in comparison to cells cultured on impermeable surfaces in both cell lines. However, application of ALI conditions did not further enhance the villin mRNA-level in both cell lines. On the other hand, in a comprehensive study Chantret et al. (1988) analysed twenty cell lines with the focus on epithelial polarity, villin protein expression and enterocyte differentiation. Villin was present in all cell lines grown under standard culture conditions, but differences in the expression level of villin were found. Surprisingly, the expression of villin was not always in 
parallel with the morphological appearance of microvilli (Chantret et al. 1988). In our experimental approach, IPEC-1 showed short microvilli but no detectable villin expression independent of the cell culture method. However, in IPEC-J2, we detected longer microvilli and a strong villin expression in all culture methods. The amount of villin protein was independent, but the adequate localisation of villin was dependent on the culture system (dishes $<$ conventional membranes $<$ ALI cultures). We show here for the first time that an improved oxygen supply based on the ALI culture leads to a villin localisation on the apical surface which is similarly found in vivo.

A primary function of differentiated epithelial cells is to provide a dynamic barrier between different extracellular compartments and to transport luminal nutrients like proteins and lipids (Zegers and Hoekstra 1998). In our study, we showed an increased uptake of the model protein BSA in intestinal epithelial cells cultured under ALI conditions, associated with an improved oxygen supply, in comparison to cells cultured on conventional membrane cultures. The food protein digestion in the intestine leads to a variety of fragments with different molecular sizes, for example, $\beta$-lactoglobulin results in fragments with very low molecular size such as oligopeptides or amino acids and BSA leads to large fragments with a dimension near the original size of the protein (Brandtzaeg and Tolo 1977; Hemmings and Williams 1978; Pang et al. 1981; Stern and Walker 1984). The enterocyte's brush border enzymes digest peptides and breakdown products which are transported by PepT-1 into the cytosol and finally reach the portal vein (Rubio-Aliaga and Daniel 2008). The uptake of proteins is an ATP-dependent process, therefore, our study suggests that the improved oxygen supply results in a higher availability of ATP, leading to an increased uptake of BSA. It is known that glycolysis is the main pathway to produce ATP, when oxygen supply is limited. Glycolysis produces only $1 / 15$ of the amount of ATP in comparison to that obtained during the final oxidative breakdown to $\mathrm{CO}_{2}$ and $\mathrm{H}_{2} \mathrm{O}$. The improved oxygen supply in ALI cultures is obviously leading to a switch between glycolysis and oxidative phosphorylation resulting in higher available ATP-levels. This hypothesis is supported by a recent study. Wenger (2002) showed that many genes are oxygen-regulated. One important group of genes is responsible for glucose uptake and glycolysis, such as phosphofructokinase L, GAPDH, aldolase A, phosphoglycerat kinase 1 , enolase 1 and lactate dehydrogenase A (Wenger 2002). This is in accordance with the observation that mucosal epithelial cells face an "uniquely steep oxygen gradient" due to their position between the nearly anoxic gut lumen and the highly vascularised subepithelial layer (Taylor and Colgan 2007).

Changes of cellular morphology, expression of mRNA, localisation of villin-protein and functional protein transport were investigated to observe the effects of different cell culture systems associated with an improved oxygen supply on the differentiation of IPEC-1 and IPECJ2. The study is the basis for epithelial cell cultures reflecting the gut function closely related to the in vivo situation. Therefore, this test system is essential for further studies of uptake, degradation and basolateral exocytosis of nutrients as well as mucosal antigen recognition in vitro.

Acknowledgments We thank Andrea Kröber, Anke Schmidt, Sandra Vorwerk, Anja Koeppen and Brigitte Ketzler for their technical assistance. This study was supported by the German Research Council, Collaborative Research Centre (SFB) 854-project 4b and the European Union, 7th Framework Programm, project "Interplay", grant agreement No. 227549.

Open Access This article is distributed under the terms of the Creative Commons Attribution Noncommercial License which permits any noncommercial use, distribution, and reproduction in any medium, provided the original author(s) and source are credited.

\section{References}

Bacallao R, Garfinkel A, Monke S, Zampighi G, Mandel LJ (1994) ATP depletion: a novel method to study junctional properties in epithelial tissues. I. Rearrangement of the actin cytoskeleton. J Cell Sci 107(Pt 12):3301-3313

Bader A, Hansen T, Kirchner G, Allmeling C, Haverich A, Borlak JT (2000) Primary porcine enterocyte and hepatocyte cultures to study drug oxidation reactions. Br J Pharmacol 129:331-342

Barnard JA, Warwick G (1993) Butyrate rapidly induces growth inhibition, differentiation in HT-29 cells. Cell Growth Differ 4:495-501

Basson MD, Turowski G, Emenaker NJ (1996) Regulation of human (Caco-2) intestinal epithelial cell differentiation by extracellular matrix proteins. Exp Cell Res 225:301-305

Brandtzaeg P, Tolo K (1977) Mucosal penetrability enhanced by serum-derived antibodies. Nature 266:262-263

Chantret I, Barbat A, Dussaulx E, Brattain MG, Zweibaum A (1988) Epithelial polarity, villin expression, and enterocytic differentiation of cultured human colon carcinoma cells: a survey of twenty cell lines. Cancer Res 48:1936-1942

Cheng H, Leblond CP (1974) Origin, differentiation and renewal of the four main epithelial cell types in the mouse small intestine. I. Columnar cell. Am J Anat 141:461-479

Daniel H (2004) Molecular and integrative physiology of intestinal peptide transport. Annu Rev Physiol 66:361-384

Deschenes C, Vezina A, Beaulieu JF, Rivard N (2001) Role of p27 (Kip1) in human intestinal cell differentiation. Gastroenterology 120:423-438

Fey-Lamprecht F, Groth T, Albrecht W, Paul D, Gross U (2000) Development of membranes for the cultivation of kidney epithelial cells. Biomaterials 21:183-192

Friedman GB, Taylor CT, Parkos CA, Colgan SP (1998) Epithelial permeability induced by neutrophil transmigration is potentiated by hypoxia: role of intracellular cAMP. J Cell Physiol 176:76-84

Glaum R, Wiedmann-Al-Ahmad M, Huebner U, Schmelzeisen R (2010) Tissue engineering of composite grafts: cocultivation of human oral keratinocytes and human osteoblast-like cells on laminin-coated polycarbonate membranes and equine collagen membranes under different culture conditions. J Biomed Mater Res A 93:704-715 
Gonzalez-Vallina R, Wang H, Zhan R, Berschneider HM, Lee RM, Davidson NO, Black DD (1996) Lipoprotein and apolipoprotein secretion by a newborn piglet intestinal cell line (IPEC-1). Am J Physiol 271(2 Pt 1):G249-259

Gruenert DC, Finkbeiner WE, Widdicombe JH (1995) Culture and transformation of human airway epithelial cells. Am J Physiol 268:L347-L360

Halleux C, Schneider YJ (1991) Iron absorption by intestinal epithelial cells: $1 . \mathrm{CaCo}_{2}$ cells cultivated in serum-free medium, on polyethyleneterephthalate microporous membranes, as an in vitro model. In Vitro Cell Dev Biol 27A:293-302

Hemmings WA, Williams EW (1978) Transport of large breakdown products of dietary protein through the gut wall. Gut 19:715-723

Hodin RA, Shei A, Meng S (1997) Transcriptional activation of the human villin gene during enterocyte differentiation. J Gastrointest Surg 1:433-438

Kurokowa M, Lynch K, Podolsky DK (1987) Effects of growth factors on an intestinal epithelial cell line: transforming growth factor beta inhibits proliferation and stimulates differentiation. Biochem Biophys Res Commun 142:775-782

Lewis K, McKay DM (2009) Metabolic stress evokes decreases in epithelial barrier function. Ann N Y Acad Sci 1165:327-337

Mandel LJ, Bacallao R, Zampighi G (1993) Uncoupling of the molecular 'fence' and paracellular 'gate' functions in epithelial tight junctions. Nature 361:552-555

Mandel LJ, Doctor RB, Bacallao R (1994) ATP depletion: a novel method to study junctional properties in epithelial tissues. II. Internalization of $\mathrm{Na}+, \mathrm{K}(+)$-ATPase and E-cadherin. J Cell Sci 107(Pt 12):3315-3324

Ootani A, Toda S, Fujimoto K, Sugihara H (2000) An air-liquid interface promotes the differentiation of gastric surface mucous cells (GSM06) in culture. Biochem Biophys Res Commun 271:741-746

Pang KY, Walker WA, Bloch KJ (1981) Intestinal uptake of macromolecules. Differences in distribution and degradation of protein antigen in control and immunised rats. Gut 22:1018-1024

Pestka JJ, Smolinski AT (2005) Deoxynivalenol: toxicology and potential effects on humans. J Toxicol Environ Health B Crit Rev 8:39-69

Rothkoetter HJ (2009) Anatomical particularities of the porcine immune system - a physician's view. Dev Comp Immunol $33: 267-272$
Rubio-Aliaga I, Daniel H (2008) Peptide transporters and their roles in physiological processes and drug disposition. Xenobiotica 38:1022-1042

Schierack P, Nordhoff M, Pollmann M, Weyrauch KD, Amasheh S, Lodemann U, Jores J, Tachu B, Kleta S, Blikslager A, Tedin K, Wieler LH (2006) Characterization of a porcine intestinal epithelial cell line for in vitro studies of microbial pathogenesis in swine. Histochem Cell Biol 125:293-305

Simmons NL (1982) Cultured monolayers of MDCK cells: a novel model system for the study of epithelial development and function. Gen Pharmacol 13:287-291

Sinaasappel M, van Iterson M, Ince C (1999) Microvascular oxygen pressure in the pig intestine during haemorrhagic shock and resuscitation. J Physiol 514(Pt 1):245-253

Stern M, Walker WA (1984) Food proteins and gut mucosal barrier I. Binding and uptake of cow's milk proteins by adult rat jejunum in vitro. Am J Physiol 246:G556-G562

Storch J, Zhou YX, Lagakos WS (2008) Metabolism of apical versus basolateral sn-2-monoacylglycerol and fatty acids in rodent small intestine. J Lipid Res 49:1762-1769

Taylor CT, Colgan SP (2007) Hypoxia and gastrointestinal disease. J Mol Med 85:1295-1300

Taylor CT, Lisco SJ, Awtrey CS, Colgan SP (1998) Hypoxia inhibits cyclic nucleotide-stimulated epithelial ion transport: role for nucleotide cyclases as oxygen sensors. J Pharmacol Exp Ther 284:568-575

Wenger RH (2002) Cellular adaptation to hypoxia: $\mathrm{O}_{2}$-sensing protein hydroxylases, hypoxia-inducible transcription factors, and $\mathrm{O}_{2^{-}}$ regulated gene expression. FASEB J 16:1151-1162

Yokoyama F, Sakata Y, Ootani A, Fujise T, Kakimoto T, Amemori S, Shiraishi R, Kuroki T, Tsunada S, Iwakiri R, Fujimoto K (2007) Differentiation of gastric surface mucous cells (GSM06) induced by air-liquid interface is regulated partly through mitogenactivated protein kinase pathway. J Gastroenterol Hepatol 22:2310-2315

You Y, Richer EJ, Huang T, Brody SL (2002) Growth and differentiation of mouse tracheal epithelial cells: selection of a proliferative population. Am J Physiol Lung Cell Mol Physiol 283:L1315-L1321

Zegers MM, Hoekstra D (1998) Mechanisms and functional features of polarized membrane traffic in epithelial and hepatic cells. Biochem J 336(Pt 2):257-269 